\title{
Central line associated blood stream infectious cause by multi drug resistance coagulaso- negative Staphylococci in newborns from neonatial intensive care units in Poland
}

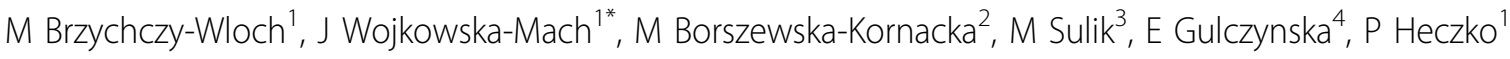 \\ From International Conference on Prevention \& Infection Control (ICPIC 2011) \\ Geneva, Switzerland. 29 June - 2 July 2011
}

\section{Introduction / objectives}

The project aims to analyze epidemiology and microbiology of Central Line Associated Blood Stream Infections (CLABSI) cause by Multi Drug Resistance CoagulasoNegative Staphyloccoci (MDRCoNS) in children with very low birth weight (VLBW).

\section{Methods}

Data collection on CLABSI in VLBW newborns was made prospectively for 2009 year. Study covered 386 neonates of birth weight $<1500 \mathrm{~g}$ in 2 Polish NICUs (A and B), among which 55 cases of CLABSI were detected. CoNS strains isolated from 26 newborns with CLABSI, were determined in blood in the automatic system Vitek, drug resistance was determined by disc diffusion method. This study was supported by a grant no. NN401615340.

\section{Results}

Birth-weight and gestational age were significantly different between newborns in NICU-A and B $(P<0.01)$. The CLABSI incidence per $1000 \mathrm{CVC} / \mathrm{pds}$ (patient days) in NICU-A and B were 8.5 and 5.2, respectively (RR1.6). CVC utilization in NICU-A and NICU-B were 0.5 and 0.4 , respectively. The most common etiological factors of CLABSI were CoNS (66\%). The dominant species were S. epidermidis (63\%), S.haemolityicus (20\%), S.warneri (8\%), S.hominis (5\%), S.xylosus (2\%) and S.capitis (2\%). Among 26 newborns with CoNS BSI, 2 children had polymicrobial infections caused by $S$. haemolyticus and S. epidermidis. Resistance to methicillin, macrolides, aminoglycosides and fluoroquinolones was detected in $98 \%, 70 \%, 78 \%$ and $43 \%$ of isolates, respectively. All methicillin resistant CoNS strains had mecA gen.

\section{Conclusion}

Understanding the epidemiology of CLABSI in VLBW neonates is a key step in development of targeted prevention strategies and reduce antibiotic consumption.

\section{Disclosure of interest}

None declared.

\section{Author details}

${ }^{1}$ Chair of Microbiology, Jagiellonian University Medical College, Krakow, Poland. ${ }^{2}$ Neonatal and Intensive Care Department, Medical University of Warsaw, Poland. ${ }^{3}$ Duchess Anna Mazowiecka, Teaching Hospital, Warsaw, Poland. ${ }^{4}$ Polish Mother's Memorial Hospital, Lodz, Poland.

Published: 29 June 2011

\section{doi:10.1186/1753-6561-5-S6-P205}

Cite this article as: Brzychczy-Wloch et al:: Central line associated blood stream infectious cause by multi drug resistance coagulaso-negative Staphylococci in newborns from neonatial intensive care units in Poland. BMC Proceedings 2011 5(Suppl 6):P205. 